\title{
In vitro phage display in a rat beta cell line: a simple approach for the generation of a single-chain antibody targeting a novel beta cell-specific epitope
}

\author{
S. Ueberberg • D. Ziegler • W. Schechinger • \\ J. W. Dietrich • S. Akinturk • H. H. Klein • S. Schneider
}

Received: 6 July 2009 / Accepted: 15 February 2010/Published online: 6 April 2010

(C) Springer-Verlag 2010

\begin{abstract}
Aims/hypothesis The aim of the present study was to evaluate in vitro phage display in a beta cell line as a novel strategy for the isolation of beta cell-specific agents/ biomarkers.

Methods A single-chain antibody (SCA) library was preincubated with AR42J cells in order to eliminate SCAs with exocrine binding properties. It was then panned against INS-1 cells to select beta cell-targeted antibodies.

Results By these means, we isolated a novel antibody, SCA $\mathrm{B} 5$, that binds rapidly $(6.0 \mathrm{~min})$ and with a 450 -fold higher specificity to beta cells relative to exocrine cells. We estimated for SCA B5 a binding affinity in the low $\mu \mathrm{mol} / 1$ range and 858 binding sites per beta cell. Confocal microscopy showed binding to the beta cell surface and confirmed subsequent internalisation. Moreover, staining of rat and human pancreatic tissue sections with SCA B5 suggests that the target epitope is presented in pancreatic beta cells of different origins. Infrared imaging revealed that labelling of beta cells with tracer SCA B5 is strictly dependent on beta cell mass. With competition assays we excluded insulin, glutamate decarboxylase, C-peptide and islet amyloid polypeptide as SCA B5 targets. In accordance with these
\end{abstract}

S. Ueberberg $\cdot$ D. Ziegler $\cdot$ W. Schechinger $\cdot$ J. W. Dietrich $\cdot$

H. H. Klein $\cdot$ S. Schneider $(\bowtie)$

Department of Internal Medicine I,

Division of Endocrinology and Metabolism,

University Hospital Bergmannsheil, Ruhr-University Bochum,

Bürkle de la Camp Platz 1,

44789 Bochum, Germany

e-mail: Stephan.Schneider@ruhr-uni-bochum.de

\section{S. Akinturk}

Department of Neuroanatomy and Molecular Brain Research, Ruhr-University Bochum,

Bochum, Germany predictions, SCA B5 homed in vivo highly selectively to normal beta cells and dysfunctional beta cells of diabetic rats. Moreover, accumulation of radioactively labelled SCA B5 in the pancreas was reduced by $80 \%$ after pre-injection with unlabelled SCA B5, thereby confirming the specific uptake in the pancreas.

Conclusions/interpretation We report a simple strategy for the generation of an SCA targeting a novel beta cellspecific epitope.

Keywords AR42J cells · Beta cell · Human islets ·

INS-1 cells $\cdot$ Phage display $\cdot$ Single-chain antibody

$\begin{array}{ll}\text { Abbreviations } \\ \text { BRASIL } & \begin{array}{l}\text { Biopanning and rapid analysis of selective } \\ \text { interactive ligands }\end{array} \\ \text { CAR } & \text { Cell associated radioactivity } \\ \text { FPG } & \text { Fasting plasma glucose } \\ \text { GAD-65 } & \text { Glutamate decarboxylase } \\ \text { IAPP } & \text { Islet amyloid polypeptide } \\ \text { ISPC } & \text { INS-1-specific phage clone } \\ K_{\mathrm{d}} & \text { Dissociation constant } \\ \text { pfu } & \text { Plaque-forming units } \\ \text { RT } & \text { Room temperature } \\ \text { SCA } & \text { Single-chain antibody }\end{array}$

\section{Introduction}

Pancreatic beta cell mass is markedly reduced in patients with type 1 or type 2 diabetes, most likely as a consequence of an increased rate of beta cell apoptosis [1, 2]. Therefore, strategies for preserving beta cell mass and allowing accurate and non-invasive assessment of beta cell mass in 
humans are critically needed. In recent years, several known islet- or beta cell-specific (or enriched) surface markers (e.g. glucagon-like peptide 1), secretory vesicle components (e.g. vesicular monoamine transporter 2) and transporter molecules (e.g. glucose transporter 2), have been evaluated for their suitability as potential islet-imaging targets [3-11]. The properties of the tracer probes (e.g. IC2 antibody) and imaging techniques (e.g. positron emission tomography) used in these studies have recently been described in detail [3, 12-14]. However, as yet none of these targets or tracer probes has allowed for successful islet imaging in humans. This is primarily because of the failure of these agents to label pancreatic beta cells with sufficient selectivity over exocrine cells (factor $>100$ is required) [7]. Thus, in order to permit the selective detection of islet beta cells within the pancreas, novel biomarkers and/or agents exhibiting high specificity for beta cells are needed.

One reason for the obvious difficulties in generating such agents is the paucity of knowledge about potential targets that are exclusively presented on the beta cell surface. Phage-display technology may be a suitable way to overcome these limitations [15-17]. By applying this approach to rats in vivo or freshly isolated rat islets in vitro, we have recently reported the isolation of single-chain antibodies (SCAs) highly specific for either pancreatic beta or alpha cells [18]. However, these approaches applied collagenase-digestion for islet isolation, which might alter substantially the surface profile of the islet cells. Therefore, in the present study, we assessed whether in vitro panning of a phage-displayed SCA library in the rat beta cell line INS-1 (enhanced by pre-absorption in AR42J cells) would lead to the isolation of SCAs targeting novel beta cell specific biomarkers. By these means, we generated one beta cellspecific SCA and compared its properties with those of the recently characterised ones.

\section{Methods}

Phage library The human SCA library (Tomlinson Library I, University of Cambridge, UK) represents $1.47 \times 10^{8}$ different SCAs fused to the pIII coat protein of a bacteriophage. The controls were a phage clone without an insert (Tomlinson library I), four beta cell-specific SCAs (SCA B1-B4) and a control SCA identified previously [18].

Cell culture Cells were grown as follows. INS-1 cells (C. Wollheim, Geneva, Switzerland) were grown in RPMI 1640 (+ glutamine) with $10 \%$ (vol./vol.) FCS, penicillin/ streptomycin and vitamins. Alpha TC1 cells (ATCC, Manassas, VA, USA) were cultured in DMEM (low glucose) with $10 \%$ FCS (vol./vol.), penicillin/streptomycin, $15 \mathrm{mmol} / 1 \mathrm{HEPES}$ and $0.1 \mathrm{mmol} / \mathrm{l}$ non-essential amino acids. AR42J and beta TC6 cells were grown in DMEM (high glucose) with $10 \%$ (vol./vol.) FCS, penicillin/streptomycin and vitamins (all from PAA, Paschingen, Austria). Cells were detached with cold trypsin $(0.05 \%$ trypsin, $0.53 \mathrm{mmol} / 1$ EDTA-4Na) $12 \mathrm{~h}$ prior to conducting the assays, washed with PBS and then stored in a $50 \mathrm{ml}$ tube with appropriate medium at $37^{\circ} \mathrm{C}$ and $5 \% \mathrm{CO}_{2}$.

Library screening AR42J cells $\left(10^{6}\right)$ were resuspended in DMEM without FCS, transferred to a $1.5 \mathrm{ml}$ tube and incubated with phage $\left(10^{12}\right.$ plaque-forming units $\left.[\mathrm{pfu}] / \mathrm{ml}\right)$ for $30 \mathrm{~min}$ at room temperature (RT). Cells were pelleted by centrifugation $(400 \times g$ for $5 \mathrm{~min})$ and supernatant fractions containing phage were incubated again with $1 \times$ $10^{6}$ AR42J cells in DMEM without FCS for $30 \mathrm{~min}$. Subsequently, the phage-cell suspension was centrifuged and the supernatant fractions containing phage were incubated with $1 \times 10^{6}$ INS-1 cells in RPMI without FCS for $2 \mathrm{~h}$ at RT before the cells were pelleted again, washed twice with PBS and lysed by the addition of $0.5 \mathrm{ml}$ PBS containing $100 \mathrm{mmol} / \mathrm{l}$ Tris- $\mathrm{HCl}(\mathrm{pH} 2.2)$. Subsequently, TG1 bacteria were infected with the eluted phage and plated on $2 x T Y$ agar with $1 \%$ glucose (wt/vol.) and $100 \mu \mathrm{g} / \mathrm{ml}$ ampicillin. After an overnight incubation at $37^{\circ} \mathrm{C}$, colonies were determined to monitor the progress of each round of library panning, and the recovered phage was amplified for use in the next round [19]. Finally, 50 phage clones each from panning rounds 1,3 and 5 were randomly selected and sent to GENterprise (Mainz, Germany) for DNA sequencing.

Binding of phage in vitro The binding selectivity of phage clones to cell lines (INS-1, beta TC6, AR42J and alpha TC1) was analysed with the biopanning and rapid analysis of selective interactive ligands (BRASIL) method [20]. For experiments, cells $\left(1 \times 10^{6}\right)$ were re-suspended in appropriate medium without FCS, transferred to a $1.5 \mathrm{ml}$ tube and incubated with a selected phage clone $\left(1 \times 10^{9} \mathrm{pfu} / \mathrm{ml}\right)$ for $4 \mathrm{~h}$ on ice. Subsequently, the cell-phage suspension was transferred to the top of a non-miscible organic lower phase ( $n$-dodecane/bromo-dodecane 1:90.8 (vol./vol.); $d=$ $1.017 \mathrm{~g} / \mathrm{ml}$ ) and centrifuged at $12,000 \times \mathrm{g}$ for $10 \mathrm{~s}$ at $4^{\circ} \mathrm{C}$. The tube was snap frozen in liquid nitrogen, the bottom of the tube sliced off and the cell-phage pellet recovered and grown as described [19]. On the following day the number of colonies was counted. Background binding was determined in the presence of a control phage $\left(1 \times 10^{9} \mathrm{pfu} / \mathrm{ml}\right)$ and subtracted from each data point.

Production of SCAs HB2151 bacteria (optical density at $600 \mathrm{~nm}=0.4)$ were infected with $10 \mu \mathrm{l}$ of a monoclonal 
phage clone and colonies were further grown in 2 xTY $(100 \mu \mathrm{g} / \mathrm{ml}$ ampicillin and $1 \%$ [wt/vol.] glucose). Isopropyl $\beta$-D-thiogalactoside (1 mmol/l; AppliChem, Darmstadt, Germany) was added to induce SCA production. The supernatant fraction containing the antibodies was purified by metal affinity chromatography (Nunc ProPur; Nunc, Langenselbold, Germany) and purity checked by SDS gel electrophoresis and western blotting.

Binding properties of SCAs in vitro SCAs $(100 \mu \mathrm{g}$ protein) were radiolabelled with iodine-125 $(100 \mathrm{mCi} / \mathrm{ml}$; Hartmann Analytics, Braunschweig, Germany) and their binding properties to cell lines (INS-1, beta TC6 and AR42J) were analysed as previously described [8, 18]. Briefly, $1.5 \mathrm{ml}$ tubes containing cells $\left(10^{6}\right)$ in $200 \mu 1$ medium without FCS were placed in an incubator $\left(5 \% \mathrm{CO}_{2}\right.$ and $\left.37^{\circ} \mathrm{C}\right)$ for $30 \mathrm{~min}$. Subsequently, radiolabelled SCAs were added and cells were further incubated for $10 \mathrm{~min}$ (or as noted). Accumulation of radiolabel was determined by separating the cell-associated radioactivity (CAR) from the free radioactivity by transferring the cell suspension to a $1.0 \mathrm{ml}$ tube containing a layer of oil comprising $n$ dodecane/bromo-dodecane (1:90.8 [vol./vol.]; $d=1.017 \mathrm{~g} / \mathrm{ml}$ ), and centrifuged for $10 \mathrm{~s}$ at $12,000 \times g$. The tube was snap frozen in liquid nitrogen, the bottom of the tube sliced off and the radioactivity of the tube containing the cell pellet was counted in a gamma counter. Retention was determined similarly except that after incubating the cells for $10 \mathrm{~min}$ in the presence of radiolabel, cells were washed twice with PBS and further incubated in radiolabel-free media prior to spinning the cells through the oil layer. In order to account for the cell-type-specific cell volume we normalised the CAR $(\mathrm{cpm} / \mathrm{cell})$ with the average volume (in fl). The average cell volume was determined in each experiment by a CASY 1 cell counter (CASY; Innovatis, Reutlingen, Germany), which produced cell volume information on the basis of cell frequency distribution. Background binding was determined in the presence of high concentrations of unlabelled control SCA $(100 \mu \mathrm{g})$ and subtracted from each data point.

In order to determine binding affinity, CAR was measured in the presence of varying concentrations of labelled antibody $(0.1-50 \mu \mathrm{g})$ with or without pre-incubation of high concentrations of unlabelled SCAs $(100 \mu \mathrm{g})$ at $4^{\circ} \mathrm{C}$. The number of molecules bound per cell, $B$, was calculated as $B=\mathrm{CAR} \times$ $A v /\left(\mathrm{SA} \times 10^{6}\right.$ cells $)$ where $A v$ is Avogadro's number, and SA is the specific activity of the labelled antibody in $\mathrm{cpm} / \mathrm{fmol}$. The dissociation constant $\left(K_{\mathrm{d}}\right)$ and the maximal number of molecules bound/cell $\left(B_{\max }\right)$ was fitted by non-linear regression according to the following equation $B=B_{\max } \times$ $T /\left(K_{\mathrm{d}}+T\right)$ where $T$ is the concentration of free antibody in the media $(\mathrm{nmol} / \mathrm{l})$. Non-linear fitting was performed with the packages 'graphics' and 'stats' of the statistical programming language $\mathrm{R}$.
For competition assays, unlabelled SCAs $(100 \mu \mathrm{g})$, human insulin (100 $\mu \mathrm{g}$; Roche, Mannheim, Germany), human glutamate decarboxylase (rH-GAD-65; $100 \mu \mathrm{g}$; Diamyd Diagnostics, Stockholm, Sweden), rat islet amyloid polypeptide (IAPP; $100 \mu \mathrm{g}$; Bachem, Weil am Rhein, Germany) or rat C-peptide $(100 \mu \mathrm{g}$; Bachem) was added to the cells before radiolabelled SCA B5 was added.

Fluorescence microscopy INS-1 or AR42J cells were seeded on culture dishes $(50,000$ cells/dish; Greiner, Frickenhausen, Germany), with appropriate medium and placed in an incubator $\left(5 \% \mathrm{CO}_{2}\right.$ and $\left.37^{\circ} \mathrm{C}\right)$ for $48 \mathrm{~h}$. For experiments, medium was aspirated, SCA B5 $(2 \mu \mathrm{g} / \mathrm{ml})$ resuspended in $100 \mu \mathrm{l}$ medium without added FCS and incubated either at $4^{\circ} \mathrm{C}$ or $37^{\circ} \mathrm{C}$ for $10 \mathrm{~min}$. The culture dishes were washed with PBS and cells fixed by adding ice-cold 4.0\% (vol./vol.) formaldehyde for $15 \mathrm{~min}$. Subsequently, the cells were permeabilised with $0.1 \%$ Triton X100 for $10 \mathrm{~min}$ and an anti-myc fluorescently labelled secondary $\operatorname{IgG}(2 \mu \mathrm{g} / \mathrm{ml}$; AlexaFluor 488 conjugate; Millipore) was added. Finally, cells were analysed using a confocal microscope (Axiovert $100 \mathrm{M}$; ZEISS LSM 510 Laser Module).

Infrared imaging SCA B5 or the control SCA was labelled with infrared dye 800 (CW Labeling Kit; Li-cor Biosciences, Lincoln, USA). Increasing amounts of INS-1 cells $\left(10^{4}-10^{8}\right)$ in medium containing $5.6 \mathrm{mmol} / 1$ glucose and $10^{6}$ INS-1 cells in medium with increasing concentrations of glucose $(2.8-16.8 \mathrm{mmol} / \mathrm{l})$ were grown on eight well chamber slides and incubated for $48 \mathrm{~h}$ in a $\mathrm{CO}_{2}$ incubator at $37^{\circ} \mathrm{C}$. Subsequently, cells were fixed with $4 \%$ (vol./vol.) formaldehyde for $20 \mathrm{~min}$ at RT, permeabilised with $0.1 \%$ Triton X-100 and incubated with labelled SCA B5 $(1 \mu \mathrm{g} / \mathrm{ml})$ for $1 \mathrm{~h}$. The signal was detected at $800 \mathrm{~nm}$ by an infrared imaging system (Odyssey, Li-cor Biosciences). The mean intensity of control cells that contain control-SCAlabelled INS-1 cells was subtracted from the intensity of wells containing INS-1cells labelled with SCA B5 to correct for any background signal not related to SCA B5 staining.

In vivo biodistribution Female non-diabetic $\mathrm{CD}$ rats $(n=5$, 6 weeks old, $\sim 220 \mathrm{~g})$ and male diabetic ZDF rats $(n=5$, 6 weeks old, $\sim 200 \mathrm{~g}$, fasting plasma glucose [FPG] 5.4 \pm $1.1 \mathrm{mmol} / \mathrm{l} ; n=5,9$ weeks old, $2300 \mathrm{~g}$, FPG $9.0 \pm 1.8 \mathrm{mmol} / \mathrm{l}$; $n=5,12$ weeks old, $\sim 300 \mathrm{~g}$, FPG $18.2 \pm 2.5 \mathrm{mmol} / \mathrm{l}$ ) were purchased from Charles River (Sulzfeld, Germany). The rats were injected intravenously with SCA B5 (100 $\mu \mathrm{g}$ protein/animal). Rats were killed $2 \mathrm{~h}$ after injection and organs (as stated) were harvested and fixed with formalin. 
In another experiment, $100 \mu \mathrm{g}$ of ${ }^{125}$ I-labelled SCA B5 (specific activity $18.5 \mathrm{MBq}$ ) was injected intravenously into non-diabetic CD rats $(200-250 \mathrm{~g}, n=6)$. A blood probe was taken $2 \mathrm{~h}$ post-injection, the animals were killed and the organs (as stated) harvested and placed into test tubes. Tubes containing tissues were weighed and counted for radioactivity with a gamma counter. Data were calculated as percentage injected dose per gram organ weight. For competition experiments $(n=3)$, unlabelled SCA B5 (100 $\mu \mathrm{g}$ /animal) was administered $15 \mathrm{~min}$ prior to the radiolabelled SCA B5 antibody. Animal experiments were approved by the local government.

Immunohistochemistry Staining of paraffin-embedded rat and human tissue sections $(5 \mu \mathrm{m})$ were performed as follows. The use of human tissue was approved by the local ethics committee. Sections were deparaffinised and subsequently permeabilised by heating in the microwave oven in antigen-unmasking solution $\mathrm{pH} 6$ and cooling for 45 min. Blocking was done for $1 \mathrm{~h}$ at $24^{\circ} \mathrm{C}$ with PBS containing $2 \%(\mathrm{wt} / \mathrm{vol}$.) BSA. Primary and secondary antibodies were diluted in PBS with $2 \%$ BSA. Primary antibodies were incubated at $4^{\circ} \mathrm{C}$ overnight, except for anti-insulin, anti-glucagon and anti-somatostatin antibodies with an incubation period of $1 \mathrm{~h}$ at $37^{\circ} \mathrm{C}$. Secondary antibodies were incubated for $30 \mathrm{~min}$ at $24^{\circ} \mathrm{C}$ as well as $\mathrm{Cy} 2-$ and $\mathrm{Cy} 3$-conjugated streptavidin reagents. The following primary antibodies and dilutions were used: SCA B5, 1:200; mouse anti-c-myc, 1:200 (New England Biolab, Frankfurt am Main, Germany); guinea pig antiswine-insulin, 1:400 (Dako, Carpinteria, CA, USA); mouse anti-glucagon, 1:200 (Thermo Scientific, Rockford, IL, USA) and rat anti-somatostatin antibody, 1:25 (Millipore GmbH; Schwalbach; Germany). Secondary antibodies were mouse anti-c-myc, 1:200; biotinylated anti-rabbit $\operatorname{IgG}$ and biotinylated anti-mouse $\mathrm{IgG}, 1: 200$ (Linaris $\mathrm{GmbH}$, Wertheim-Bettingen, Germany); Cy3-conjugated goat anti-mouse IgG, 1:200 (Jackson Immuno Research Europe, Newmarket, UK); Cy3-conjugated goat anti-guinea pig IgG, 1:800 (Jackson Immuno Research Europe); Cy3conjugated goat anti-rat IgG (heavy and light chains), 1:100 (Jackson Immuno Research Europe). The tertiary reagent was Cy2-conjugated streptavidin, 1:200 (Jackson Immuno Research Europe). Tissue slides were analysed using a Zeiss Axioplan microscope.

Statistics Parametric comparisons of continuous data were calculated with Student's $t$ test for unpaired data with unequal variance. The relationship between beta cell mass and fluorescence signal intensity was analysed by linear regression analysis. All calculations have been performed with KaleidaGraph 4.0.3 for Macintosh Computers (Synergy Software, Reading, PA, USA).

\section{Results}

Generation of beta cell-targeting SCAs In order to generate novel agents that bind specifically to beta cells, a subtractive selection strategy was applied in which the phage library encoding for $1.47 \times 10^{8}$ SCAs was first incubated with AR42J cells in order to absorb phage with exocrine binding properties. Subsequently, the supernatant fraction from this incubation $\left(\sim 1 \times 10^{5} \mathrm{pfu} / \mathrm{ml}\right)$ was incubated with INS-1 cells. Over five rounds of this selection process a substantial increase of the number of phage bound to INS-1 cells was detected (from $1.2 \times 10^{2}$ to $1.2 \times$ $10^{8}$; Fig. 1a), indicating enrichment of INS-1-cell-binding phage. Subsequently, 50 phage clones from each of panning rounds 1,3 and 5 were randomly selected for DNA sequencing. Surprisingly, all of these clones yielded identical DNA sequence, thereby giving rise to one single INS-1-specific phage clone (ISPC, the clone being named ISPC5 = SCA B5; the amino acid sequence is shown in Fig. 1b). Of note, repetitive runs of this protocol yielded identical results.

In order to confirm the binding selectivity of the ISPC5 phage to beta cells, binding of ISPC5 to INS-1, beta TC6, alpha TC1 and AR42J cells was tested with the BRASIL method in vitro (Fig. 1c). For these experiments cells and media were kept on ice to minimise post-binding events, such as receptor-mediated internalisation. The assay showed a 17-fold higher specificity for INS-1 or beta TC6 relative to alpha TC1 and AR42J cells for the ISPC5 phage $(p<0.0001)$.

Binding properties of SCAs in vitro As beta cell-specific delivery requires removal of SCA B5 from the context of the ISPC5 phage, HB2151 bacteria were infected with ISPC5 phage and isopropyl $\beta$-D-thiogalactoside was added to induce SCA B5 production. Subsequently, the supernatant fraction containing SCA B5 was purified by metal affinity chromatography. Next, soluble SCA B5 was radioactively labelled and its binding properties were tested in INS-1, beta TC6 and AR42J cells in vitro. These characteristics were then compared with those of the beta cell-specific SCAs identified previously [18]. Of note, in contrast to the BRASIL method, this assay was performed at $37^{\circ} \mathrm{C}$ (except studies for binding affinity and binding sites). By these means, a rapid binding with a binding halftime of 6 min but no washout phase was found for SCA B5, indicating internalisation of SCA B5 (Fig. 2a). The binding selectivity of SCA B5 to INS-1 or beta TC6 was 450 -fold higher relative to AR42J cells (Fig. 2b) and was thus comparable with the beta cell-specific SCAs evaluated previously. For SCA B5, binding saturation could be demonstrated after pre-incubation with unlabelled SCA B5 (Fig. 2c). Importantly, competition assays revealed no 


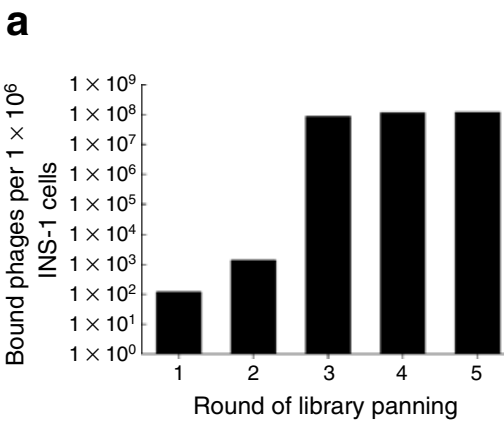

Fig. 1 a Phage-library screening for beta cell-specific phage clones. Five rounds of selection were carried out and a substantial increase in bound phage per $1 \times 10^{6}$ INS- 1 cells was observed. b The amino acid sequence of the ISPC5 phage (SCA B5). Amino acids are shown in one-letter codes. Positions that are diverse in the repertoire are marked in bold. Boxes indicate the complementarity-determining region (CDR). Heavy and light chain regions are underlined (heavy chain shown with dashed underlining, light chain shown with dotted

binding inhibition of radiolabelled SCA B5 by preincubation with unlabelled beta cell-specific SCAs identified previously (SCA B1-B4, Fig. 2c), suggesting that the binding of these SCAs was at least at different epitopes of the same antigen. Moreover, the addition of insulin, GAD65, C-peptide or IAPP did not inhibit binding of SCA B5 to INS-1 cells, indicating that these proteins do not present the epitope recognised by SCA B5 (Fig. 2c). Finally, SCA B5 had a slightly higher binding affinity $\left(K_{\mathrm{d}} 3.6 \mathrm{vs} 4.1 \mu \mathrm{mol} / \mathrm{l}\right)$, but a lower maximal number of binding sites ( 858 vs 7,023 molecules/cell) compared with SCA B1.

Next, binding of SCA B5 to INS-1 cells was analysed by confocal microscopy. For this purpose, cells were grown on underlining). At the C-terminus the SCA contains a His tag (blue) and a c-myc tag (red) $\mathbf{c}$ In vitro binding of ISPC5 phage or a control phage without an insert to INS-1 (black bars), beta TC6 (grey bars), alpha TC1 (white bars) and AR42J cells (hatched bars). Cells and media were kept on ice to minimise post-binding events, such as receptor-mediated internalisation. The ISPC5 phage showed highly specific binding to INS-1 and beta TC6 cells, whereas no binding to alpha TC1 or AR42J cells was detected. $n=6,{ }^{\dagger} p<0.0001$

culture dishes and subsequently incubated for $10 \mathrm{~min}$ with SCA B5 at either $4^{\circ} \mathrm{C}$ or $37^{\circ} \mathrm{C}$. After fixation of the cells, SCA B5 was detected with fluorescently labelled secondary IgG. By this means, the rapid binding of SCA B5 to the beta cell surface and subsequent internalisation was shown (Fig. 3). Control reactions with AR42J cells and without the primary antibody were negative.

To determine the relationship between the number of beta cells and imaging signal, increasing numbers of INS1 cells $\left(1 \times 10^{4}-1 \times 10^{8}\right)$ were grown on chamber slides and incubated for $1 \mathrm{~h}$ with fluorophore-labelled SCA B5. The signal intensity was detected by an infrared scanner. By this means, a strong correlation between the signal

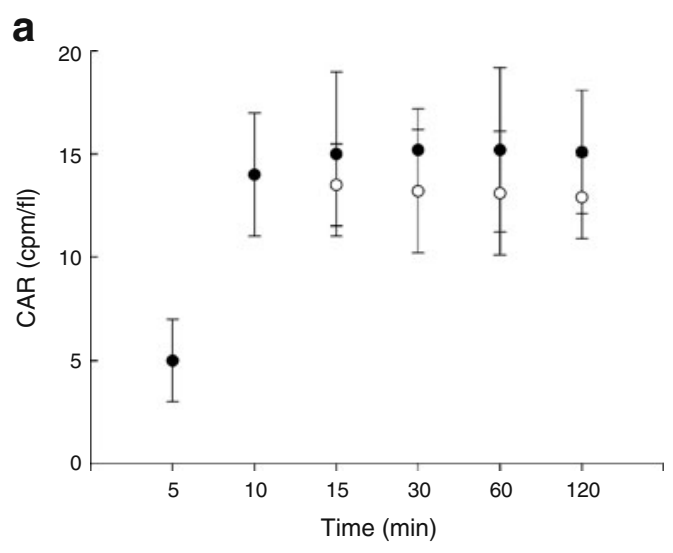

Fig. 2 Binding properties of ${ }^{125}$ I-labelled SCA B5 to different endocrine and exocrine cell lines in vitro. a Rapid binding $\left(t_{1 / 2}=\right.$ $6.0 \mathrm{~min}$ ) of SCA B5 to INS-1 cells (black circles), but no washout (white circles) was detected, indicating internalisation. b Highly selective binding of SCA B5 to INS-1 (black bars) and beta TC6 cells (grey bars) was detected $(* * * p<0.001$ vs AR42J cells [hatched
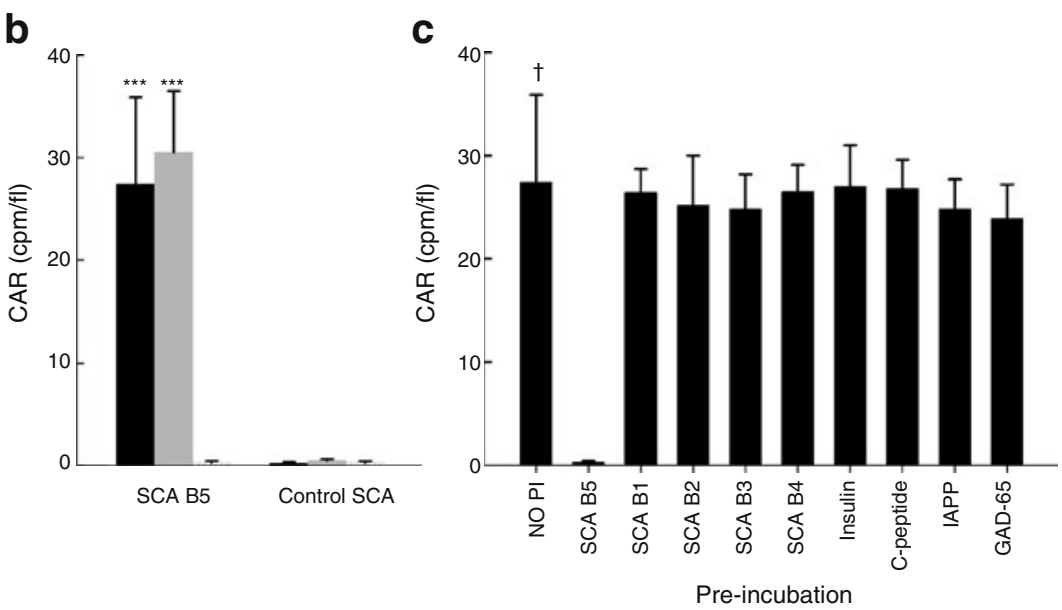

bars]). $\mathbf{c}$ Binding saturation to INS-1 cells was demonstrated for SCA B5 by pre-incubation with unlabelled SCA B5 († $p<0.0001$ vs cells pre-incubated with SCA B5). In contrast, competition assays involving pre-incubation with SCA B1-B4, insulin, C-peptide, IAPP and GAD-65 demonstrated no inhibition of binding of SCA B5 to INS-1 cells 

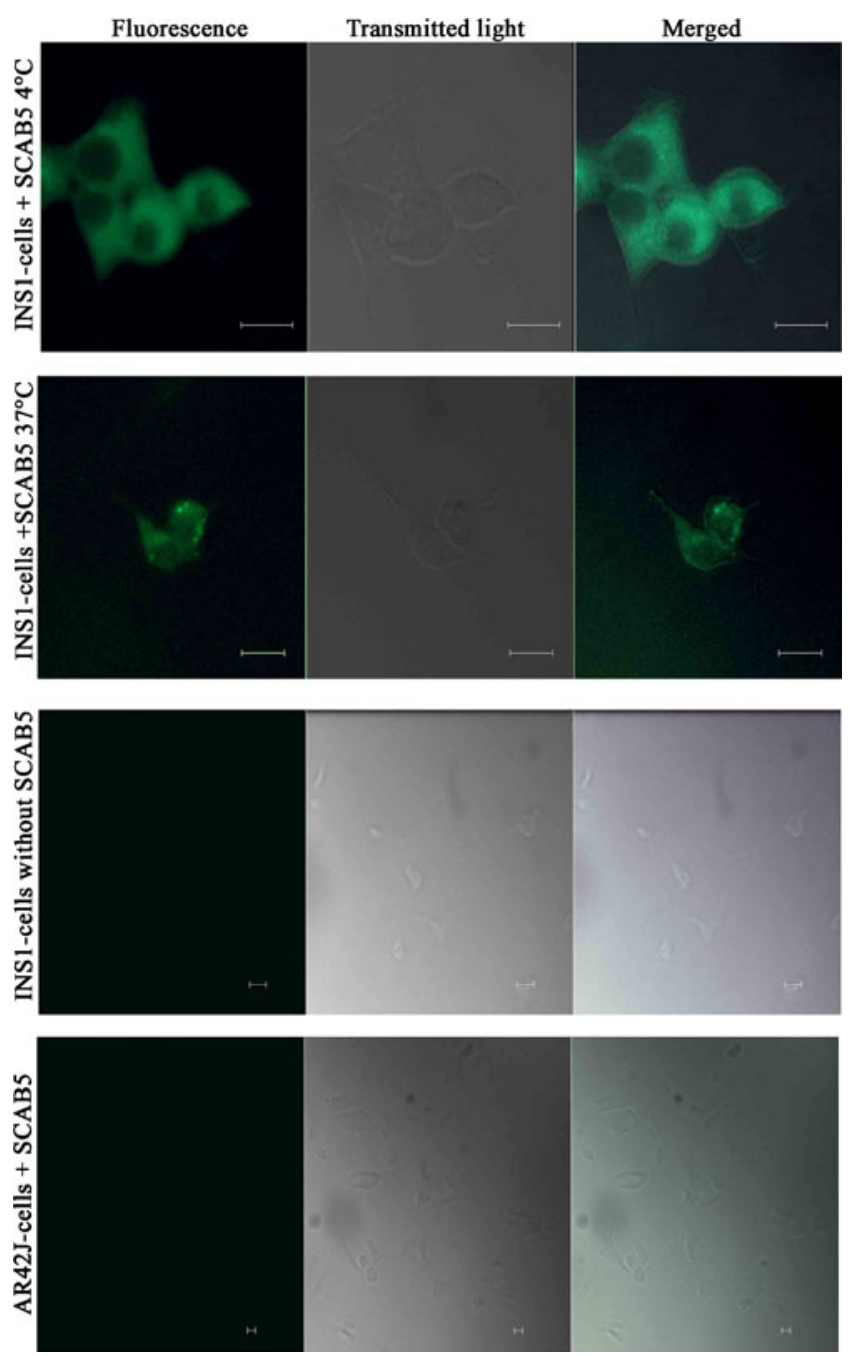

Fig. 3 Binding analyses by confocal laser microscopy. INS-1 cells were incubated with SCA B5 for 10 min either at $4^{\circ} \mathrm{C}$ or $37^{\circ} \mathrm{C}$. After fixation of the cells, SCA B5 was detected with a fluorescently labelled secondary $\operatorname{IgG}$ antibody. At $4^{\circ} \mathrm{C}$ binding to the cell surface was shown, whereas at $37^{\circ} \mathrm{C}$ internalisation was detected. Control reactions without the primary antibody or with AR42J cells were negative. Scale bars, $10 \mu \mathrm{m}$

intensity and the number of beta cells was detectable $\left(r^{2}=\right.$ 0.823 , Fig. 4). The overall intensity has a clear tendency to increase with increasing numbers of beta cells. In contrast, the signal remained unchanged when $10^{6}$ INS- 1 cells were incubated for $48 \mathrm{~h}$ with increasing concentrations of glucose $(2.8-16.8 \mathrm{mmol} / \mathrm{l})$. These data suggest that the labelling signal is dependent on beta cell mass but not beta cell function.

In vivo biodistribution For translation into clinical practice, specific binding of SCA B5 to beta cells in vivo would be required. Therefore, SCA B5 was injected intravenously into non-diabetic $\mathrm{CD}$ rats for a circulation time of $2 \mathrm{~h}$. Subsequently, the animals were killed and the pancreas and control organs were prepared for immunohistochemical analyses. SCA B5 was clearly identifiable in the islets and the signal overlapped with insulin production, whereas no co-localisation with glucagon was detectable, suggesting that SCA B5 was binding exclusively to beta cells (Fig. 5). Of note, no binding to control organs (liver, kidney, spleen, lung, thyroid, stomach, brain, parotid gland; data not shown) was detectable and experiments with the control SCA did not reveal binding to islets or other structures.

In another set of experiments, the biodistribution of radiolabelled SCA B5 was analysed by injection into nondiabetic rats. Subsequently, pancreas and control organs were harvested for detection of radioactivity. In accordance with the in vitro predictions and the immunohistochemistry data, SCA B5 accumulated selectively in the pancreas and
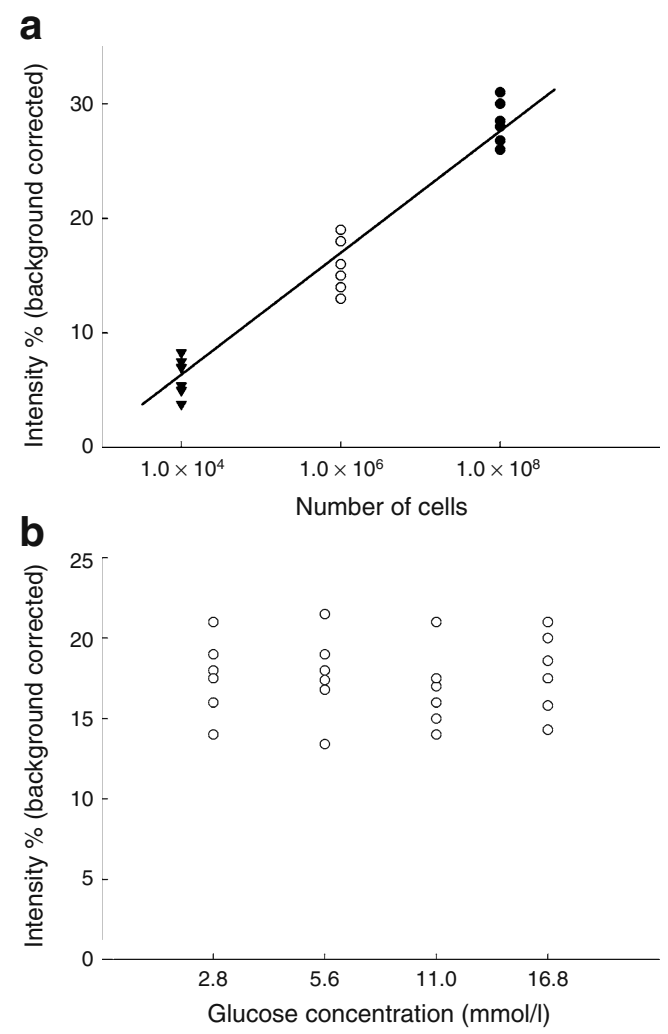

Fig. 4 Imaging with SCA B5 labelled with infrared dye 800. INS-1 cells were labelled in vitro with tracer SCA B5 and the signal intensity was detected by an infrared imaging system. a Linear regression analyses show a close correlation between increasing amounts of INS-1 cells $\left(1 \times 10^{4}-1 \times 10^{8}\right)$ and signal intensity $\left(r^{2}=823\right)$. b The signal intensity remained unchanged when $1 \times 10^{6}$ INS- 1 cells were incubated with increasing concentrations of glucose. Each data point represents one well of an eight well chamber slide. To correct for any background signal not related to SCA B5 staining, the mean signal intensity of wells containing INS-1 cells with fluorophore-labelled control SCA was subtracted from each data point 
Fig. 5 Immunofluorescence analyses of the biodistribution of SCA B5 or the control SCA after intravenous injection in a non-diabetic $C D$ rat $(n=5$ rats per group, 30-40 sections and 60-80 islets per rat). The presence of SCA was determined by immunohistochemistry using an anti-myc antibody, because the SCAs contained a c-myc tag. In the pancreas SCA B5 co-localised exclusively with the insulin-producing beta cells, whereas no binding to glucagon-producing cells or exocrine cells was detected (staining in green colour for SCA with an anti-c-myc antibody and nuclei were stained blue with DAPI). All images are at $\times 40$ magnification
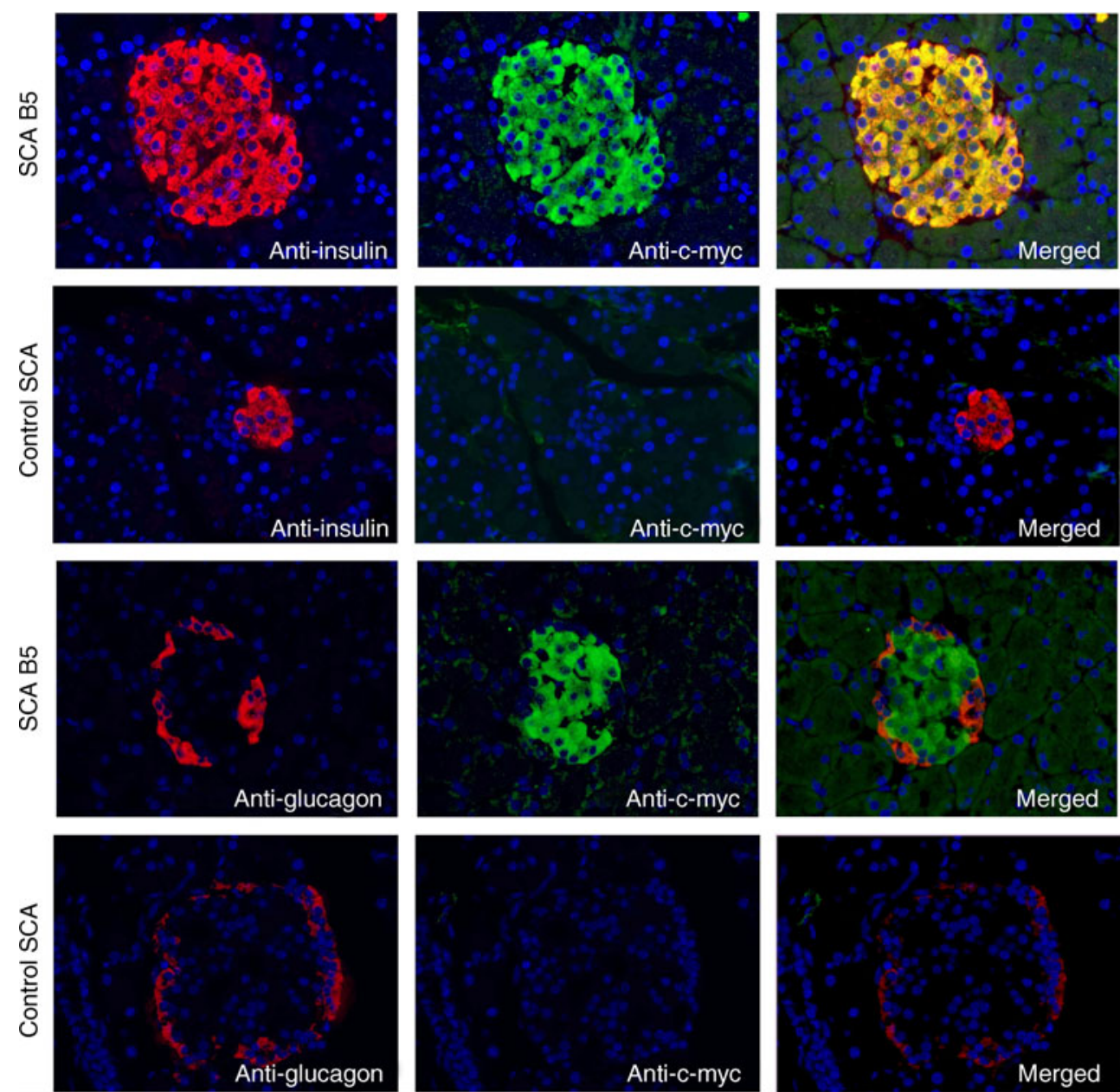

Table 1 Biodistribution of ${ }^{125}$ I-labelled SCA B5 in non-diabetic rats

\begin{tabular}{lcc}
\hline Tissue & \multicolumn{2}{l}{$\begin{array}{l}\text { Biodistribution of }{ }^{125} \text { I-labelled SCA B5 } \\
(\% \text { injected dose/g tissue })\end{array}$} \\
\cline { 2 - 3 } & Without pre-injection & With pre-injection \\
\hline Pancreas & $5.12 \pm 1.01$ & $0.95 \pm 0.18^{* * *}$ \\
Stomach & $0.69 \pm 0.24$ & $0.57 \pm 0.17$ \\
Spleen & $0.55 \pm 0.18$ & $0.58 \pm 0.26$ \\
Kidney & $0.38 \pm 0.13$ & $0.44 \pm 0.17$ \\
Liver & $0.71 \pm 0.28$ & $0.64 \pm 0.22$ \\
Brain & $0.26 \pm 0.09$ & $0.33 \pm 0.14$ \\
Blood & $0.23 \pm 0.11$ & $0.22 \pm 0.15$ \\
Thyroid & $0.27 \pm 0.15$ & $0.31 \pm 0.11$ \\
\hline
\end{tabular}

${ }^{125}$ I-labelled SCA B5 was injected into the tail vein of non-diabetic CD rats $(n=6)$ and, after $2.0 \mathrm{~h}$, tissues were harvested as described in Methods

For competition experiments $(n=3)$, unlabelled SCA B5 was injected 15 min prior to injection of the radiolabelled probe

$* * * p<0.001$ vs without pre-injection exhibited no affinity for the control tissues (Table 1). Moreover, probe accumulation in the pancreas was reduced by $80 \%$ after pre-injection with unlabelled SCA B5, thereby confirming the specific uptake of SCA B5 in the pancreas.

A valuable feature of beta cell-targeting agents would be that they allow the fate of beta cells to be followed during the development of diabetes. Therefore, we assessed the ability of SCA B5 to target beta cells of ZDF rats of different ages. As in the previous experiments, SCA B5 was injected intravenously and its presence in organs of interest was determined by immunohistochemistry. As shown in Fig. 6, SCA B5 was selectively identifiable within the cytoplasm of the pancreatic beta cells of normoglycaemic (6 weeks old), mildly hyperglycaemic (9 weeks old) and severely hyperglycaemic (12 weeks old) ZDF rats, whereas no binding to exocrine cells and other control tissues (e.g. liver; data not shown) was detectable. Of note, the SCA B5 was not identifiable in destroyed islet beta cells of ZDF rats (data not shown), providing further evidence that the signal is dependent on the beta cell mass. Taken together, these results indicate that 
Fig. 6 Evaluation of binding to pancreatic beta cells of SCA B5 after intravenous injection in diabetic $Z D F$ rats $(n=5$ rats per group, 30-40 sections and $60-80$ islets per rat). The presence of SCAs was determined by immunohistochemistry using an anti-myc antibody, because the SCAs contained a c-myc tag. SCA B5 selectively co-localised with insulin-producing beta cells and showed no binding to other endocrine or exocrine cells, irrespective of the age of the animals. DAPI stains nuclei blue. All images are at $\times 20$ magnification
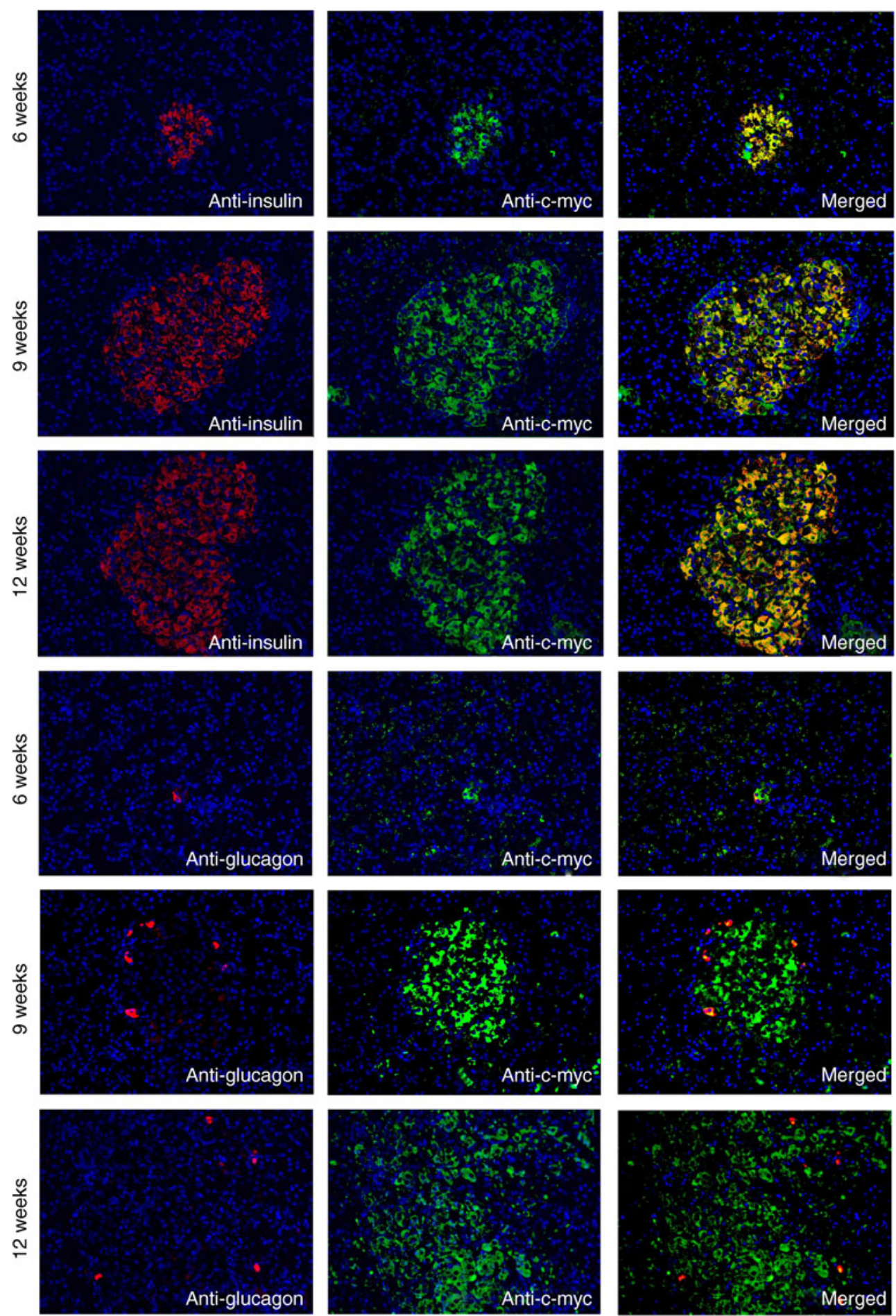

SCA B5 highly selectively targets normal beta cells as well as dysfunctional beta cells during diabetes development.

Binding of SCA B5 to human and rat pancreatic tissue in situ To further prove specific binding of SCA B5 to rat beta cells and its potential applicability in humans, rat and human pancreatic tissue samples were co-stained by immunohistochemistry using SCA B5 as well as specific anti-insulin, anti-glucagon and anti-somatostatin antibodies. SCA B5 was exclusively identifiable within the islets and co-localised with insulin-producing cells, but not with glucagon- and somatostatin-producing cells (Fig. 7). These data strongly suggest that SCA B5 binds to a molecule that is produced in pancreatic beta cells of different origins. 
Fig. 7 Immunofluorescence staining for binding of SCA B5 to human (representative pancreas from a non-diabetic donor) and rat islets (representative pancreas from a nondiabetic CD rat) in situ. The presence of SCA was determined by immunohistochemistry using an anti-myc antibody, because the SCAs contained a cmyc tag. SCA B5 co-localised with insulin, but not glucagon or somatostatin staining. DAPI stains nuclei blue. All images are at $\times 40$ magnification
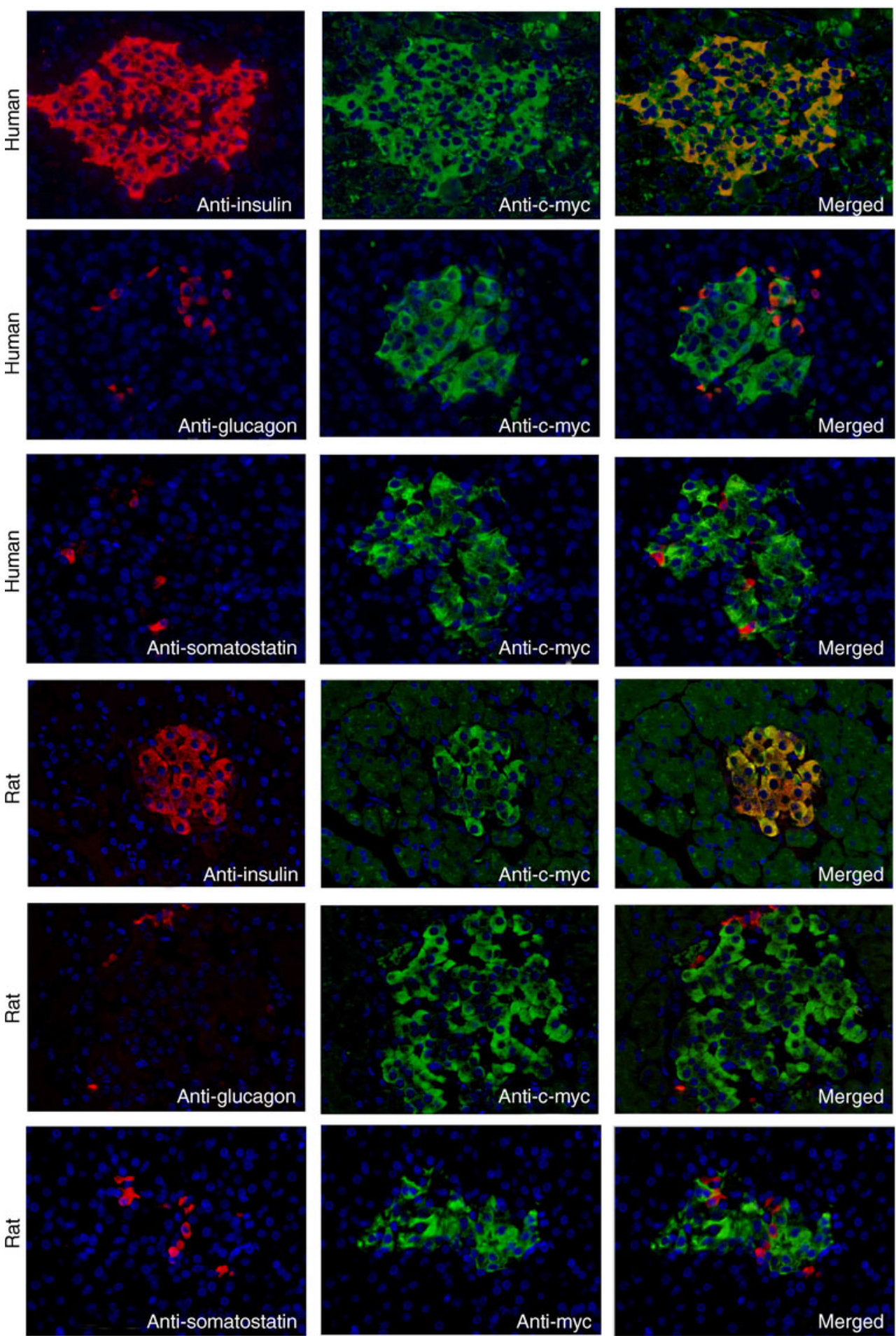

\section{Discussion}

The field of imaging technology has made tremendous progress in recent years, allowing for the non-invasive and accurate detection of small structures, such as specific brain cell populations. However, as yet the lack of sufficiently specific beta cell targets and/or tracer molecules has prevented the successful application of these powerful technologies to beta cell imaging in humans [13, 14]. Recently, we reported the successful isolation of beta and alpha cell-specific SCAs by screening of a phage library on primary rat islets in vitro and in vivo [18]. A key element of the method used for the generation of these SCAs was the use of collagenase. Particularly, collagenase disrupts the endothelial cell lining of the intra-islet capillaries during the isletisolation process and thus eliminates phage bound to the 
endothelium. This is supported by the finding that all collagenase-based approaches generated alpha and/or beta cell-specific agents $[18,21]$, whereas the approaches that abandoned collagenase identified agents selectively targeting the islet endothelium $[22,23]$. However, collagenase alters the surface profile of pancreatic islets, and thus we anticipate that the identification of valuable beta or alpha cell-specific targeting agents could be prevented.

Therefore, in this proof-of-concept study we report a simple and very time-efficient in vitro panning strategy, in which a phage-displayed SCA library was pre-incubated with the rat exocrine cell line AR42J in order to eliminate SCAs with exocrine binding properties and then panned against the rat beta cell line INS-1 to select beta celltargeted antibodies. By these means, we isolated SCA B5, a novel antibody that binds rapidly $\left(t_{1 / 2}=6.0 \mathrm{~min}\right)$ and with a 450 -fold higher specificity for beta cells relative to exocrine cells. These highly promising features are comparable with those of the beta cell-specific SCAs (SCA B1 - SCA B4) reported previously. However, binding of SCA B5 to beta cells was not inhibited by these SCAs, indicating that binding occurs at least via different binding pockets within the same cell-surface antigen. This claim is supported by the finding that the novel antibody SCA B5 had a slightly higher binding affinity for beta cells compared with the SCA B1 (both in the low $\mu \mathrm{mol} / 1$ range), but a lower maximal number of binding sites (by a factor of ten). Confocal microscopy images provide further evidence for binding of SCA B5 to the beta cell surface and confirm its subsequent internalisation. In particular, the incubation of INS-1 cells with varying concentrations of radiolabelled SCA B5 revealed a capacity of $>630,000$ SCAs to be internalised per beta cell. Moreover, staining of rat and human pancreatic tissue sections with SCA B5 suggests that the target epitope is produced in pancreatic beta cells of different origins. Finally, infrared imaging of INS-1 cells indicates that labelling of beta cells with tracer SCA B5 is strictly dependent on beta cell mass. Taken together, although the binding affinity of the novel antibody SCA B5 for beta cells is below that of full antibodies or its fragments [8], SCA B5 has promising features (i.e. required beta cell selectivity, rapid binding and strong correlation with beta cell mass) that qualify for specific labelling of beta cells.

Our impression that SCA B5 represents a novel highly promising agent was strengthened by the finding that, following intravenous administration, SCA B5 targeted normal beta cells of non-diabetic CD rats in vivo, as well as dysfunctional beta cells of ZDF rats, whereas no binding or uptake to control tissues was detected. The specificity of this approach was confirmed by additional in vivo experiments showing that more than $80 \%$ of the pancreatic radiolabelling intensity could be inhibited by preadministration of unlabelled SCA B5.

Even though the method applied in this study is novel, a theoretical concern could be that the antibodies resulting from this panning approach might recognise a known beta cell target that has already been explored in previous studies. Against this, by means of various competition assays, we could rule out that SCA B5 targets insulin, GAD-65, C-peptide or IAPP. However, the identification of the respective target is still highly important to estimate the diagnostic and/or therapeutic potential of this novel SCA. Unfortunately, as yet none of the generated SCAs has immunoprecipitated any protein in western blotting or classic immunoprecipitation, suggesting that the targeted epitopes are structure sensitive.

In summary, we report a phage-panning approach in the rat beta cell line INS-1 as a novel and simple strategy for the generation of islet-targeted agents. The novel beta cellspecific antibody SCA B5 generated by this approach offers a promising perspective for non-invasive targeting of islets (e.g. in imaging) that, however, has to be shown in future studies. Moreover, this panning strategy applied to other cells lines (e.g. alpha TC1) and/or performed with other phage libraries (e.g. peptide-based) may set the route for the development of novel agents and the identification of as yet unknown beta or alpha cell-specific biomarkers.

Acknowledgements This work was supported by research grants of the Ruhr-University Bochum (FoRUM to S. Schneider), the Beta cellBiology Consortium of the NIH (DK072473 to S. Schneider), the Deutsche Forschungsgemeinschaft (SCHN 702/2-1 to S. Schneider) and the European Foundation for the Study of Diabetes (EFSD/MSD to S. Schneider and EFSD/Novartis to H. H. Klein) and the Menarini Projektförderung (to S. Schneider) of the German Diabetes Association.

Duality of interest S. Schneider holds a patent application on the SCAs described. The remaining authors declare that there is no duality of interest associated with this manuscript.

\section{References}

1. Weir GC, Bonner-Weier S, Leahy JL (1990) Islet mass and function in diabetes and transplantation. Diabetes 39:401-405

2. Butler AE, Janson J, Bonner-Weier S et al (2003) $\beta$-cell deficit and increased $\beta$-cell apoptosis in humans with type 2 diabetes. Diabetes 52:102-110

3. Schneider S (2008) Efforts to develop methods for in vivo evaluation of the native $\beta$-cell mass. Diabetes Obes Metab 10 (Suppl 4):109-118

4. Schneider S, Feilen PJ, Schreckenberger M et al (2005) In vitro and in vivo evaluation of novel glibenclamide derivatives as imaging agents for the non-invasive assessment of the pancreatic islet cell mass in animals and humans. Exp Clin Endocrinol Diabetes 113:388-395

5. Schneider S, Ueberberg S, Korobeynikov A et al (2007) Synthesis and evaluation of a glibenclamide glucose-conjugate: a potential 
new lead compound for substituted glibenclamide derivatives as islet imaging agents. Regul Pept 139:122-127

6. Wängler B, Schneider S, Thews O et al (2004) Synthesis and evaluation of $\left[{ }^{18} \mathrm{~F}\right]$ repaglinide: a promising radioligand for quantification of pancreatic $\beta$-cell mass with positron emission tomography (PET). Nucl Med Biol 31:639-647

7. Sweet IR, Cook DL, Lernmark A et al (2004) Systematic screening of potential beta cell imaging agents. Biochem Biophys Res Commun 314:976-983

8. Hampe CS, Wallen AR, Schlosser M, Ziegler M, Sweet IR (2005) Quantitative evaluation of a monoclonal antibody and its fragment as potential markers for pancreatic $\beta$-cell mass. Exp Clin Endocrinol Diabetes 113:381-387

9. Gotthardt M, Lalyko G, van Eerd-Vismale J et al (2004) A new technique for in vivo imaging of specific GLP-1 binding sites: first results in small rodents. Regul Pept 137:162-167

10. Souza F, Simpson N, Raffo A et al (2006) Longitudinal noninvasive PET-based beta cell mass estimates in a spontaneous diabetes rat model. J Clin Invest 116:1506-1513

11. Moore A, Bonner-Weir S, Weissleder R (2001) Noninvasive in vivo measurement of beta cell mass in mouse model of diabetes. Diabetes 50:2231-2236

12. Malaisse WJ (2001) On the track to the $\beta$-cell. Diabetologia 44:393-406

13. Souza F, Freeby M, Hultman K et al (2006) Current progress in non-invasive imaging of beta cell mass of the endocrine pancreas. Curr Med Chem 13:2761-2773

14. Virostko J, Jansen ED, Powers AC (2006) Current status of imaging pancreatic islets. Curr Diab Rep 6:328-332

15. Ueberberg S, Schneider S (2010) Phage library-screening: a powerful approach for generation of targeting-agents specific for normal pancreatic islet-cells and islet-cell carcinoma in vivo. Regul Pept 160:1-8

16. Kolonin MG, Saha PK, Chan L, Pasqualini R, Arap W (2004) Reversal of obesity by targeted ablation of adipose tissue. Nat Med 10:625-632

17. Arap W, Kolonin MG, Trepel M et al (2002) Steps toward mapping the human vasculature by phage display. Nat Med $8: 121-127$

18. Ueberberg S, Meier JJ, Waengler C et al (2009) Generation of novel single-chain antibodies by phage-display technology to direct imaging agents highly selective to pancreatic beta- or alphacells in vivo. Diabetes 58:2324-34

19. Pasqualini R, Arap W, Rajotte D, Ruoslathi E (2000) In vivo selection of phage display libraries. In: Barbas C, Burton D, Silverma G, Scott J (eds) Phage display: a laboratory manual. Cold Spring Harbor Laboratory Press, New York, pp 22.122.24

20. Giordano RJ, Marina CV, Lahdenranta J, Pasqualini R, Arap W (2001) Biopanning and rapid analysis of selective interactive ligands. Nat Med 7:1249-1253

21. Samli KN, McGuire MJ, Newgard CB, Johnston SA, Brown KC (2005) Peptide-mediated targeting of the islets of Langerhans. Diabetes 54:2103-2108

22. Joyce JA, Laakkonen P, Bernasconi M, Bergers G, Ruoslahti E, Hanahan D (2003) Stage-specific vascular markers revealed by phage display in a mouse model of pancreatic islet tumorigenesis. Cancer Cell 4:393-403

23. Yao VJ, Yao VJ, Ozawa MG, Trepel M, Arap W, McDonald DM, Pasqualini R (2005) Targeting pancreatic islets with phage display assisted by laser pressure catapult microdissection. Am J Pathol 166:625-636 